\title{
BMJ Open Perinatally acquired HIV-positive status disclosure and associated factors in Dire Dawa and Harar, Eastern Ethiopia: a health facility-based cross-sectional study
}

\author{
Melkamu Merid Mengesha, ${ }^{1}$ Yadeta Dessie, ${ }^{1}$ Aklilu Abrham Roba ${ }^{2}$
}

To cite: Mengesha MM, Dessie Y, Roba AA. Perinatally acquired HIV-positive status disclosure and associated factors in Dire Dawa and Harar, Eastern Ethiopia: a health facility-based crosssectional study. BMJ Open 2018;8:e019554. doi:10.1136/ bmjopen-2017-019554

- Prepublication history for this paper is available online. To view these files please visit the journal online (http://dx.doi org/10.1136/bmjopen-2017019554).

Received 12 September 2017 Revised 13 June 2018 Accepted 25 July 2018

Check for updates

(c) Author(s) (or their employer(s)) 2018. Re-use permitted under CC BY-NC. No commercial re-use. See rights and permissions. Published by BMJ.

${ }^{1}$ School of Public Health, College of Health and Medical Sciences, Haramaya University, Harar,

Ethiopia

${ }^{2}$ School of Nursing and

Midwifery, College of Health and Medical Sciences, Haramaya University, Harar, Ethiopia

Correspondence to

Melkamu Merid Mengesha;

melkamumrd@gmail.com

\section{ABSTRACT}

Objectives The aim of this study was to assess the level and factors associated with caregivers' disclosure of perinatally HIV-infected (PHIV+) children's seropositive status.

Design We conducted a cross-sectional study in five public health facilities providing HIV treatment and care in Dire Dawa and Harar, Eastern Ethiopia. The data were collected from 310 caregivers through face-to-face interviews and record reviews. Data analyses were done using STATA V.14.2 and statistical significance was declared at $p$ value $<0.05$.

Results The study revealed that the level of PHIV+ diagnosis disclosure was $49.4 \%$ (95\% Cl 43.8 to 54.9$)$. Mean age at disclosure was 11.2 years. Disclosure level was higher among children who frequently asked about their health status (aOR (adjusted OR) 2.04, 95\% Cl 1.04 to 4.03) and when caregivers knew other people who had a disclosure experience (aOR 2.49, 95\% $\mathrm{Cl} 1.17$ to 5.32 ). Disclosure level was less among children of 12 years or below (aOR $0.04,95 \% \mathrm{Cl} 0.02$ to 0.09 ) and among caregivers practising deception about the children's HIV positive status (aOR $0.38,95 \% \mathrm{Cl} 0.19$ to 0.74 ).

Conclusion Only half of the caregivers disclosed their child's PHIV+ diagnosis. To facilitate disclosure, caregivers should be counselled about the appropriate age of disclosure and related misconceptions that hinder it. It is also apparent that caregivers need to be guided as to how to address children's frequent questions about their health status. These interventions can be made in a one-on-one approach or through patient group counselling when they come to get healthcare services.

\section{INTRODUCTION}

Globally, at the end of 2016, an estimated 2.1 million adolescents aged $10-19$ years were HIV infected, and 1.7 million were in sub-Saharan Africa. ${ }^{1}$ Only a few decades ago, due to lack of treatment options, diagnosis with HIV for children was like a death sentence. ${ }^{2}$ Perinatal HIV infection (PHIV+) has dramatically decreased with the advent of highly effective antiretroviral treatment (ART). However, it
Strengths and limitations of this study

- The study presents the level of perinatal HIV infection (PHIV+) diagnosis disclosure and associated factors in resource-limited settings where such aspects have been overlooked in HIV care and treatment.

- All caregivers in public health facilities providing HIV/AIDS care and treatment services in the study settings were included, increasing the generalisability of our findings.

- As we measured disclosure based on the caregiver's report, the study may have suffered from a social desirability bias.

- Health facility-related factors that might affect the study outcome were not assessed and need to be addressed in the future.

was reported that only three in five HIV-positive pregnant and breastfeeding women received ART in 2014, leading to continued perinatal HIV transmission. ${ }^{3}$ Effective treatment means that children with PHIV+ who are living anywhere in the world can now safely pass through adolescence and enter into adulthood. ${ }^{2}$ The continued burden of new PHIV+ and the transition of the HIV infection from a rapidly fatal to a chronic condition has brought challenges in the treatment and care of these groups of children. ${ }^{24}$

The increasing survival of children with PHIV+ intoadolescence and adulthood has brought significant adherence challenges to the long-term treatment, as well as developmental issues including, among many, peer relationships, puberty and sexuality. ${ }^{56}$ On the other hand, another important challenge, as more of these children reach adolescence and adulthood, is disclosure of their HIV status. $^{7}{ }^{8}$ HIV diagnosis disclosure entails communication about a potentially life-threatening, stigmatised and transmissible illness. 
Consequently, caregivers fear that such communication may create distress for children and reveal a family secret related to HIV infection. ${ }^{9}$ PHIV+ diagnosis disclosure is further complicated by lack of skill on the caregiver's side to undertake disclosure. Furthermore, poor access to training and lack of clear guidelines for healthcare workers on PHIV+ diagnosis disclosure might have played a role in delaying disclosure. ${ }^{10}$ Delay in disclosure has implications both for the clinical outcome as well as transmission of the infection, as children enter the pubertal stage and start romantic relationships and ultimately sexual intercourse. ${ }^{10-13}$

In resource-limited settings, only a few children with PHIV+ know their HIV-positive status ${ }^{14}{ }^{15}$ despite several studies reporting the benefits of disclosure both to the caregiver and the child. Benefits of disclosure reported in previous research include improved adherence, providing answers to children's questions, fulfilling the child's right to know and the child being able to protect him/herself or others. ${ }^{16}{ }^{17}$ Research also suggests that HIV-infected children who know their status may be better able to seek social support and have improved coping skills. ${ }^{18} 19$

Previous studies have reported factors related to caregivers' disclosure of PHIV+. However, the findings come from context-specific qualitative studies or from quantitative studies with small sample sizes making generalisation difficult. ${ }^{20}$ The child-related factors of disclosure in previous studies include age, level of maturity/awareness, level of education, duration since HIV diagnosis and initiation of ART. ${ }^{14151721}$ Similarly, caregiver-related factors include fear of the negative effects of disclosure and feeling worried about disclosure or unprepared to disclose. ${ }^{14} 1722$

Despite several studies conducted elsewhere, there is a dearth of information on the magnitude of PHIV+ diagnosis disclosure and associated factors specifically in eastern Ethiopia. Previous studies conducted on PHIV+ diagnosis disclosure in Ethiopia considered children below the age of 15 years or were conducted using a small sample size. ${ }^{1423-25}$ In our study, all children had started ART, which was reported as one of the factors associated with disclosure. ${ }^{17}$ Therefore, we aimed to assess the proportion of PHIV+ diagnosis disclosure and its correlates among caregivers who had PHIV+ children between the ages of 6 and 18 years.

\section{MATERIALS AND METHODS \\ Study setting and design}

A cross-sectional study was conducted from 1 February to 30 April 2016 in five public health facilities in Eastern Ethiopia: four hospitals (two in Harar and two in Dire Dawa) and one health centre in Dire Dawa. The adult HIV prevalence in Dire Dawa City Administration Council was $4.0 \%$ (4.3\% for women, $3.7 \%$ for men) and it was $2.8 \%$ (3.8\% for women, $1.7 \%$ for men) in Harari Regional State. ${ }^{26}$ According to a projection estimate for the year 2016, there were 456 HIV-positive children between the ages of 0 and 14 years in the urban areas of Harar and 1029 in Dire Dawa. ${ }^{27}$

\section{Participants}

Primary caregivers who had PHIV+ children between the ages of 6 and 18 years were included. A caregiver who had more than one PHIV+ child in the specified age range reported information only about one randomly selected child to avoid problems with the estimation of the level of disclosure. In this study, a primary caregiver is defined as a person who is responsible for all needs of the child, takes care of the child and lives with the child. All children for whom information was collected had started on ART.

\section{Sample size}

Four public hospitals (two in Harar and two in Dire Dawa) and one health centre located in an urban area with at least 10 eligible caregivers were included. All eligible caregivers in these facilities were included. Accordingly, a total of 325 caregivers were identified and 310 provided information: 210 from Dire Dawa and 100 from Harar.

\section{Data collection}

Data were collected through face-to-face interviews with primary caregivers using a structured questionnaire and a checklist from the children's and caregivers' medical record card in the ART units of the respective health facilities. Data collectors were nurses who had been working in the ART units of the respective health facilities for at least 3 years. They received a 1-day orientation on the objectives of the study, on data collection techniques and on ways to avoid interviewer bias during data collection. Onsite supervisors both in Dire Dawa and Harar study sites checked the proper administration of the data collection and checked the completeness and consistency of the questionnaires.

\section{Measurement and definitions}

Caregiver-related and child-related sociodemographic and HIV-positive status data were collected during the caregiver interviews. Furthermore, the primary caregiver's HIV diagnosis test results (if applicable) and the child's HIV diagnosis and ART status were confirmed from the medical record card using the patient's unique ART number. The sociodemographic data collected included age, sex and educational status of the caregiver and the child, caregiver's religion, ethnicity, relation to the child and the child's biological parent survival.

We assessed children's HIV-positive status disclosure and other disclosure variables using items shown in table 1 .

In this study, deception was defined as a caregiver's intentional false answer to a child's question regarding his/her health status or intentionally attributing a child's health problem to other unrelated health-related conditions. Disclosure was said to happen when a caregiver told his/her child that the child has HIV/AIDS by naming the disease. 
Table 1 Disclosure-related caregiver questionnaire items administered in the perinatal HIV infection diagnosis disclosure study, East Ethiopia, 2016

Items 1-7 were administered to ALL caregivers

1. Does the child ever ask questions about his/her
health status?
2. Do you ever intentionally give the child wrong
information in response to questions about his/her
health status?
Does the child know that the name of his/her illness
is HIV?
At what age do you perceive that a perinatally
acquired HIV-positive child should know that he/she
has HIV?
Do you know someone (eg, a caregiver like you) who
has disclosed perinatally acquired HIV status?
W. What do you think about the importance of a third
6. Whon's presence to assist disclosure?
7. Whom do you prefer to seek help from for HIV status
disclosure?

Items 8-9 were administered ONLY to disclosed caregivers (answered 'YES' to item 3)

8. Duration since the child has known that he/she has
HIV (in months)
9. Child age at disclosure (in years)

\section{Statistical analysis}

The data were entered in to EpiData V.3.1 and cleaning and analysis were done using STATA V.14.2. The outcome variable was disclosure dichotomised into disclosed $(\mathrm{Yes}=1)$ and not disclosed $(\mathrm{No}=0)$. A multivariable binary logistic regression model was applied to identify independent factors. Multicollinearity was tested using the variance inflation factor (VIF) and 'children's educational status' was dropped from the final model as it had a VIF as high as 6.37. The Hosmer-Lemeshow goodness-of-fit test was used to assess model adequacy. Statistical significance was declared at $\mathrm{p}$ value $<0.05$.

\section{Ethical issues}

Ethical approval was obtained. Written informed consent was obtained from each eligible caregiver before the data collection. No personal identifiers were collected, and data confidentiality were strictly maintained.

\section{Patient and public involvement}

Growing literature on PHIV+ disclosure indicates challenges in providing disclosure-related services in resource-limited settings. The authors had closely observed these in one of the hospitals in the study settings and hence designed the conduct of this study. Research assistants working in ART units recruited study participants. To communicate the findings, a summary of key results will be translated into local languages and will be communicated to health facilities in the study settings.
Table 2 Sociodemographic characteristics of caregivers and their perinatally HIV-infected children, East Ethiopia, 2016

\begin{tabular}{|c|c|c|}
\hline Variables & Response category & $\mathrm{n}=310(\%)$ \\
\hline \multicolumn{3}{|l|}{$\begin{array}{l}\text { Caregivers' } \\
\text { characteristics }\end{array}$} \\
\hline \multirow[t]{3}{*}{ HIV serostatus } & Positive & 229 (73.9) \\
\hline & Negative & $76(24.5)$ \\
\hline & Don't know & $5(1.6)$ \\
\hline $\begin{array}{l}\text { Age in years, median } \\
\text { (IQR) }\end{array}$ & $38(15)$ & \\
\hline \multirow[t]{2}{*}{ Sex } & Male & $56(18.1)$ \\
\hline & Female & $254(81.9)$ \\
\hline \multirow[t]{3}{*}{ Educational status } & No formal education & $85(27.4)$ \\
\hline & Primary education & $111(35.8)$ \\
\hline & Secondary and above & $114(36.8)$ \\
\hline \multirow[t]{2}{*}{ Religion } & Christian & $226(72.9)$ \\
\hline & Muslim & $84(27.1)$ \\
\hline \multirow[t]{3}{*}{ Ethnicity } & Amhara & $172(55.5)$ \\
\hline & Oromo & $88(28.5)$ \\
\hline & Other* & $50(16.2)$ \\
\hline \multirow[t]{2}{*}{ Relation to the child } & Biological caregiver & $209(67.4)$ \\
\hline & Non-biological caregiver & $101(32.6)$ \\
\hline \multicolumn{3}{|l|}{$\begin{array}{l}\text { Children's } \\
\text { characteristics }\end{array}$} \\
\hline Age, mean (SD) & $12.07( \pm 3.06)$ & \\
\hline \multirow[t]{2}{*}{ Sex } & Male & $146(47.1)$ \\
\hline & Female & $164(52.9)$ \\
\hline \multirow[t]{4}{*}{ Educational status } & Not school going & $8(2.6)$ \\
\hline & Primary, below grade 5 & $144(46.5)$ \\
\hline & Primary, grade 5 to 8 & $126(40.6)$ \\
\hline & Secondary and above & $32(10.3)$ \\
\hline \multirow[t]{4}{*}{ Parent/s alive } & Both parents alive & $145(46.8)$ \\
\hline & Only mother alive & $75(24.2)$ \\
\hline & Only father alive & $51(16.5)$ \\
\hline & Both parents not alive & 39 (12.6) \\
\hline
\end{tabular}

${ }^{*}$ Guraghe, Somali, Tigray and Harari.

\section{RESULTS}

\section{Sociodemographic characteristics}

Of the 325 eligible caregivers, 15 caregivers did not keep their appointments during the study period, making the response rate $95.4 \%(310 / 325)$. Most of the caregivers, $81.9 \%$ (254/310), were women, and $67.4 \%$ (209/310) were biological parents. Seventy four per cent $(229 / 310)$ of the caregivers were HIV positive and their median age was 38 years. More than half of the PHIV+ children were girls: $52.9 \%(164 / 310)$. The mean age of children was 12 years and $12.6 \%(39 / 310)$ had lost both biological parents (table 2). 
Table 3 Level of perinatal HIV infection diagnosis disclosure by caregiver and child sociodemographic characteristics, East Ethiopia, 2016

\begin{tabular}{|c|c|c|c|c|c|}
\hline \multirow[b]{2}{*}{ Variables } & \multirow[b]{2}{*}{ Response category } & \multicolumn{2}{|l|}{ Disclosure } & \multirow[b]{2}{*}{ Pearson's $X^{2}(d f)$} & \multirow[b]{2}{*}{$P$ values } \\
\hline & & Yes=153, n (\%) & No=157, n (\%) & & \\
\hline \multicolumn{6}{|c|}{ Caregiver's characteristics } \\
\hline \multirow[t]{3}{*}{ Age in years } & $<30$ & 19 (12.4) & 29 (18.5) & $3.5(2)$ & 0.171 \\
\hline & 30 to 44 & $84(54.9)$ & $89(56.7)$ & & \\
\hline & $\geq 45$ & $50(32.7)$ & $39(24.8)$ & & \\
\hline \multirow[t]{2}{*}{ Sex } & Male & $27(17.7)$ & $29(18.5)$ & $0.04(1)$ & 0.85 \\
\hline & Female & $126(82.4)$ & $128(81.5)$ & & \\
\hline \multirow[t]{3}{*}{ Educational status } & No formal education & $38(24.8)$ & $47(29.9)$ & $1.13(2)$ & 0.569 \\
\hline & Primary education & $58(37.9)$ & $53(33.8)$ & & \\
\hline & Secondary and above & $57(37.3)$ & $57(36.3)$ & & \\
\hline \multirow[t]{2}{*}{ Religion } & Christian & $127(83.0)$ & $99(63.1)$ & $15.6(1)$ & $<0.001$ \\
\hline & Muslim & $26(17.0)$ & 58 (36.9) & & \\
\hline \multirow[t]{3}{*}{ Ethnicity } & Amhara & $91(59.5)$ & $81(51.6)$ & $2.2(2)$ & 0.33 \\
\hline & Oromo & $41(26.8)$ & $47(29.9)$ & & \\
\hline & Other ${ }^{*}$ & $21(13.7)$ & $29(18.5)$ & & \\
\hline \multirow[t]{2}{*}{ Relation to child } & Biological caregiver & $104(68.0)$ & $105(66.9)$ & $0.04(1)$ & 0.837 \\
\hline & Non-biological caregiver & 49 (32.0) & $52(33.1)$ & & \\
\hline \multicolumn{6}{|l|}{ Child's characteristics } \\
\hline \multirow[t]{2}{*}{ Sex } & Male & 65 (42.5) & $81(51.6)$ & $2.58(1)$ & 0.108 \\
\hline & Female & $88(57.5)$ & $76(48.4)$ & & \\
\hline \multirow[t]{3}{*}{ Age in years } & 6 to 9 & $8(5.2)$ & $69(44.0)$ & 114.6(2) & $<0.001$ \\
\hline & 10 to 12 & $28(18.3)$ & $60(38.2)$ & & \\
\hline & 13 to 18 & $117(76.5)$ & $28(17.8)$ & & \\
\hline \multirow[t]{3}{*}{ Educational status } & Did not start education & $3(2.0)$ & $31(19.8)$ & $72.0(2)$ & $<0.001$ \\
\hline & Below grade 5 & $36(23.5)$ & $82(52.2)$ & & \\
\hline & Grade 5 and above & $114(74.5)$ & $44(28.0)$ & & \\
\hline \multirow[t]{4}{*}{ Parent/s alive } & Both parents alive & 58 (37.9) & $87(55.4)$ & $10.5(3)$ & 0.015 \\
\hline & Only mother alive & $41(26.8)$ & $34(21.7)$ & & \\
\hline & Only father alive & 29 (19.9) & $22(14.0)$ & & \\
\hline & Both parents not alive & $25(16.3)$ & $14(8.9)$ & & \\
\hline
\end{tabular}

*Guraghe, Somali, Tigray and Harari.

$\mathrm{df}$, degree of freedom; significant at $\mathrm{p}$ value $<0.05$.

\section{PHIV+ diagnosis disclosure}

Overall, $49.4 \%$ (95\% CI 43.8 to 54.9) of the caregivers had disclosed PHIV+ diagnosis. The level of disclosure increased as child age increased. For example, of the total children who were reported to know their HIV-positive status, $76.5 \%$ were 13 years and above. In contrast, children below the age of 10 years constituted only $5.2 \%$. Furthermore, other caregiver and child characteristics which had some association with disclosure included a caregiver being Christian, both parents were alive and the child being grade 5 or above (table 3 ).

For school-age children (6-12 years), more boys than girls knew their HIV-positive diagnosis. Conversely, for adolescents of age 13 and above, more girls than boys knew their HIV-positive diagnosis (figure 1). The median duration since a child had his/her PHIV+ diagnosis disclosed was 24 months and the mean age at disclosure was $11.2(\mathrm{SD}= \pm 2.4)$ years.

Caregivers reported that they needed assistance in the process of PHIV+ diagnosis disclosure. Of the total caregivers, $56 \%(173 / 310)$ reported that they needed assistance. Among these, $65.9 \%(114 / 173)$ said they needed it from a healthcare worker, $17.9 \%(31 / 173)$ from a family member, $11.6 \%(20 / 173)$ from their partner, $3.5 \%$ (6/173) from an HIV-positive person and 1.2\% (2/173) from other sources.

\section{Factors associated with PHIV+ diagnosis disclosure}

The variables with $p$ value $<0.2$ in the bivariate binary logistic regression were entered into the final model. 


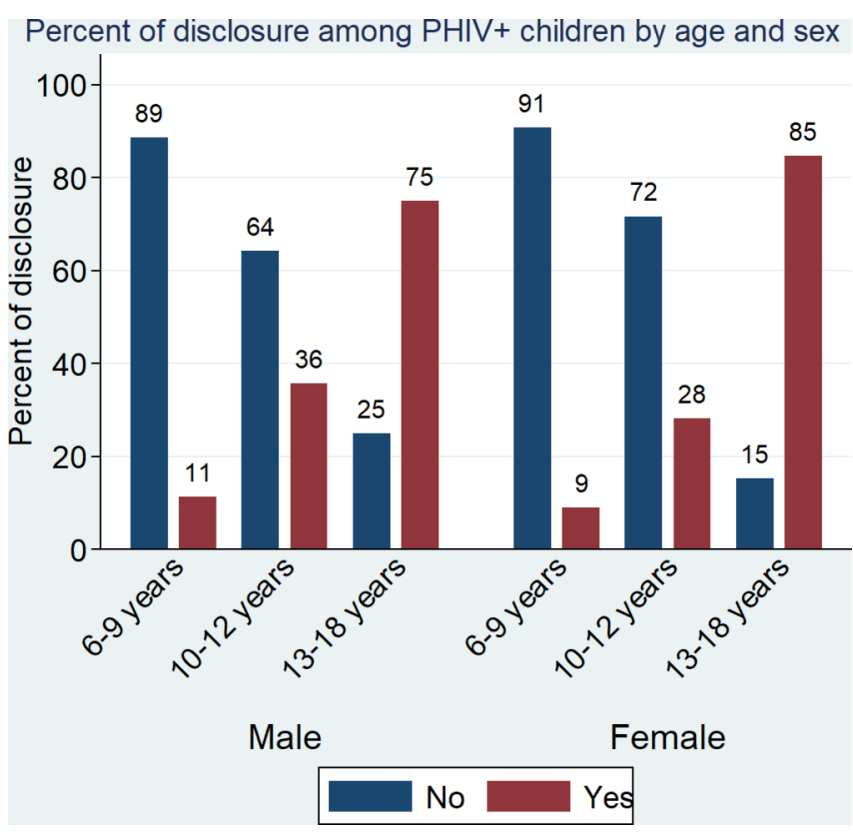

Figure 1 Level of perinatal HIV infection (PHIV+) diagnosis disclosure to children in Dire Dawa and Harar, Eastern Ethiopia, 2016. Disclosure was said to happen when a caregiver reported that the child knows the name of his/her illness is HIV/AIDS.

Factors that favour PHIV+ diagnosis disclosure in the final model were the caregiver's knowledge of a person who had disclosure experience (aOR 2.49, 95\% CI 1.17 to 5.32) and the child's inquiry about his/her health condition (aOR 2.04, 95\% CI 1.04 to 4.03). A caregiver was less likely to make disclosure if the age of the child was 12 years or less (aOR $0.04,95 \%$ CI 0.02 to 0.09 ), if the caregiver practised deception about the child's HIV-positive status (aOR 0.38, 95\% CI 0.19 to 0.74 ) and if the caregiver preferred an older child age for disclosure (10-12 years, aOR $0.30,95 \%$ CI 0.11 to 0.84 ; or $\geq 13$ years, aOR 0.06 , $95 \%$ CI 0.02 to 0.18 ) (table 4 ).

\section{DISCUSSION}

This study revealed that half of the caregivers reported full disclosure. Factors positively associated with disclosure included the child's inquiry about their health status and the caregiver's knowledge of other people with a disclosure experience. On the other hand, the caregiver's deception about the child's illness, preference of older child age for disclosure and the child being younger age hindered disclosure.

The level of disclosure identified in our study was higher compared with previous studies in Ethiopia (17.4\% to $39.5 \%),{ }^{142324}$ East Africa (26\% to $\left.43.1 \%\right),{ }^{15} 2829$ West Africa (21\% to $29 \%),{ }^{21}{ }^{30}$ South Africa $39.6 \%{ }^{31}$ and a review of 22 primary studies in low/middle-income countries $(1.7 \%$ to $41 \%) \%) .{ }^{32}$ The higher level of disclosure in our study may be attributed to the higher mean age of children. Furthermore, in our study, all children about whom information on disclosure was provided by caregivers had started ART, a factor already reported to be positively associated with disclosure ${ }^{15}$ However, the level of disclosure in this study is low compared with a $70 \%$ level of disclosure to children aged 9 to 16 years in four medical centres in New York city ${ }^{33}$ that might be related to the difference in study settings and other related factors.

In our study, children have their own HIV status disclosed when they become old enough to understand the implications of having HIV. Similar findings were reported from Ethiopia and other settings. ${ }^{14} 1523243334$ Delaying disclosure until the child is too old is against the WHO's recommendation to disclose PHIV+ diagnosis to school-age children, ${ }^{35}$ and does not follow the national guidelines recommendation that children aged 10 years and above should receive full disclosure. ${ }^{36}$ Such delay in disclosure poses a risk of an inadvertent disclosure or psychological harm for the child. ${ }^{10}$ Furthermore, it has the negative implications of losing the mental health benefits of disclosure, gaining cooperation of the child with medication adherence and improving the caregiverchild relationship. ${ }^{1237}$ More urgently, a delay in disclosure has a public health risk of transmitting the HIV infection, including drug-resistant HIV strains, as undisclosed adolescents do not have a chance to prevent transmission through safe sexual behaviours and through self-disclosure to partners. ${ }^{13} 3839$ Therefore, rather than waiting until a child is considered old enough for disclosure, consistent support for caregivers should be facilitated to prepare children for full disclosure. ${ }^{10} 38$

Deception about a child's HIV-positive status among caregivers was common in our study settings and had negatively influenced disclosure. Similar findings have been reported elsewhere. ${ }^{142428}$ A review article by Britto et al in low/middle-income countries reported deception as high as $49.5 \%$ where caregivers provided a non-HIV-related reason for explaining illness and healthcare visits. ${ }^{32}$ Deception is used by caregivers as a coping mechanism for their lack of self-efficacy to manage disclosure and fear of negative outcomes. ${ }^{24} 373940$ Deception reveals that caregivers should be assisted on how to communicate truthfully, pass on disease-related information and understand the implications of deception on future full disclosure, child behaviour and medical care. ${ }^{1037}$

This study replicated the findings of other studies that caregivers demand a third person for assistance in the disclosure process 24293237 which opens an opportunity for trained individuals to engage in and guide families through the disclosure process. Therefore, to produce a better disclosure outcome, trained healthcare workers are required to collaborate with caregivers as disclosure needs to be individualised to the child's context as discussed elsewhere.$^{29}$ Furthermore, there is a need for context-specific guidelines on disclosure which will undoubtedly affect the scope of support that healthcare workers can provide to caregivers. ${ }^{10}$

The finding that children's inquiry about their own health status triggered disclosure was consistent with other studies. ${ }^{24}$ As reported, caregivers deflect 
Open access

\begin{tabular}{|c|c|c|c|c|}
\hline Variables & cOR $(95 \% \mathrm{Cl})$ & $P$ value & aOR $(95 \% \mathrm{Cl})$ & $P$ value \\
\hline \multicolumn{5}{|l|}{ Caregiver's age in years } \\
\hline$<30$ & 0.51 (0.25 to 1.04$)$ & 0.065 & 0.92 (0.33 to 2.58$)$ & 0.871 \\
\hline $30-44$ & $0.74(0.44$ to 1.23$)$ & 0.243 & $1.56(0.67$ to 3.64$)$ & 0.307 \\
\hline$\geq 45$ & 1 & Ref. & 1 & Ref. \\
\hline \multicolumn{5}{|l|}{ Religion } \\
\hline Christian & 2.86 (1.68 to 4.87 ) & $<0.001$ & 1.75 (0.85 to 3.61$)$ & 0.130 \\
\hline Muslim & 1 & Ref. & 1 & Ref. \\
\hline \multicolumn{5}{|l|}{ Biological parent survival } \\
\hline Both parents alive & 0.37 (0.18 to 0.78$)$ & 0.008 & 0.74 (0.26 to 2.13$)$ & 0.578 \\
\hline Only mother alive & 0.68 (0.30 to 1.50$)$ & 0.334 & 1.84 (0.56 to 6.06$)$ & 0.317 \\
\hline Only father alive & 0.74 (0.31 to 1.74$)$ & 0.488 & $1.42(0.42$ to 4.77$)$ & 0.572 \\
\hline Both parents not alive & 1 & Ref. & 1 & Ref. \\
\hline \multicolumn{5}{|l|}{ Child age in years } \\
\hline$\leq 12$ & 0.07 (0.04 to 0.12 ) & $<0.001$ & 0.04 (0.02 to 0.09$)$ & $<0.001$ \\
\hline$>12$ & 1 & Ref. & 1 & Ref. \\
\hline \multicolumn{5}{|c|}{ Child asked questions about their health status } \\
\hline Yes & $1.48(0.95$ to 2.31$)$ & 0.087 & 2.04 (1.04 to 4.03$)$ & 0.039 \\
\hline No & 1 & Ref. & 1 & Ref. \\
\hline \multicolumn{5}{|l|}{ Deception } \\
\hline Yes & $0.42(0.26$ to 0.66$)$ & $<0.001$ & $0.38(0.19$ to 0.74$)$ & 0.005 \\
\hline No & 1 & Ref. & 1 & Ref. \\
\hline \multicolumn{5}{|c|}{ Caregiver's perceived appropriate age for disclosure } \\
\hline$<10$ & 1 & Ref. & 1 & Ref. \\
\hline $10-12$ & $0.31(0.14$ to 0.68$)$ & 0.003 & $0.30(0.11$ to 0.84$)$ & 0.021 \\
\hline$\geq 13$ & $0.16(0.07$ to 0.36$)$ & $<0.001$ & $0.06(0.02$ to 0.18$)$ & $<0.001$ \\
\hline \multicolumn{5}{|l|}{ Child sex } \\
\hline Male & 1 & Ref. & 1 & Ref. \\
\hline Female & 1.44 (0.92 to 2.26$)$ & 0.109 & $1.13(0.60$ to 2.15$)$ & 0.705 \\
\hline \multicolumn{5}{|c|}{ Caregiver knew someone who did a disclosure } \\
\hline Yes & 2.58 (1.48 to 4.52$)$ & 0.001 & 2.49 (1.17 to 5.32$)$ & 0.019 \\
\hline No & 1 & Ref. & 1 & Ref. \\
\hline \multicolumn{5}{|l|}{ Caregiver's ethnicity } \\
\hline Amhara & 1.55 (0.82 to 2.93$)$ & 0.176 & na & - \\
\hline Oromo & 1.20 (0.60 to 2.43$)$ & 0.602 & & \\
\hline Other* & 1 & Ref. & & \\
\hline \multicolumn{5}{|c|}{ Caregiver's educational status } \\
\hline No formal education & 0.81 (0.46 to 1.42$)$ & 0.460 & na & - \\
\hline Primary education & $1.09(0.65$ to 1.85$)$ & 0.735 & & \\
\hline Secondary and above & 1 & Ref. & & \\
\hline \multicolumn{5}{|c|}{ Caregiver's relation to the child } \\
\hline Biological parent & 1.05 (0.65 to 1.69$)$ & 0.837 & na & - \\
\hline Non-biological caregiver & 1 & Ref. & & \\
\hline \multicolumn{5}{|l|}{ Child educational status $†$} \\
\hline None & 1 & Ref. & & - \\
\hline Below grade 5 & $4.54(1.30$ to 15.81$)$ & 0.018 & na & \\
\hline Grade 5 and above & 26.77 (7.79 to 92.06$)$ & $<0.001$ & & \\
\hline
\end{tabular}

Significant at $\mathrm{p}$ value $<0.05$.

${ }^{*}$ Guraghe, Somali, Tigray, Harari.

†Child educational status was dropped from the final model due to multicollinearity issue.

aOR, adjusted OR, cOR, crude OR; na, not applicable (variables with $\mathrm{p}$ value $>=0.2$ did not enter in the multivariable logistic regression); PHIV+, perinatal HIV infection. 
illness-related information rather than provide answers to children's questions. ${ }^{142428}$ This, however, denies the right of children to know about their health status. ${ }^{37}$ Providing children with age-appropriate and consistent information means preparing them for self-care and cooperation with medication adherence ${ }^{83741}$ Conversely, denying the appropriate information in response to children's question may have an impact on the child-caregiver relationship and affect the children's quality of life as they seek to understand the truth about their health status. ${ }^{9} 103337$

Consistent with the finding reported by Marhefka $e t$ $a l,{ }^{42}$ the caregiver's knowledge of people with PHIV+ diagnosis disclosure was positively associated with disclosure. This finding showed the importance of sharing experiences among caregivers with regard to disclosure difficulties that caregivers might face. Therefore, encouraging social ties among caregivers with PHIV+ child/children may be helpful for caregivers to gain confidence and learn context-specific skills of disclosure.

The strength of this study is that it was conducted in multiple centres that provide HIV care and treatment services in the region using a relatively larger sample size making the findings more generalisable. However, this study is not without limitations which need to be reported. The outcome was assessed by the caregiver's report who might have reported positive values to assume a desirable behaviour. However, due to the relatively small number of caregivers who had children with PHIV+ perfacility surveyed, healthcare workers in the ART units knew them well and we do not expect that social desirability bias would be a significant problem. As the outcome and exposure variables were assessed at the same time, the reported associations may not show temporality. Finally, the study did not assess healthcare-related factors which might have affected caregiver's disclosure and tendency to seek counselling for disclosure, which need to be considered in future studies.

\section{CONCLUSION}

The study revealed that only half of the caregivers disclosed their child's HIV diagnosis. We recommend that caregivers should be well counselled about the recommended time and approach to facilitate timely disclosure. Caregivers should also be equipped with the appropriate knowledge and skills to address their children's questions. Healthcare workers in HIV/AIDS care and treatment units need to be specifically trained so that they can guide caregivers in the disclosure process. Furthermore, interventions involving experience sharing among caregivers on disclosure issues would be helpful, and this can be implemented in a one-on-one approach or through patient group counselling. Finally, further study is required on the challenges of disclosure from the healthcare services' perspective to establish a comprehensive package to address this issue.
Acknowledgements The authors thank the participants, data collectors and research assistants involved in this study. We are also grateful to Balewgizie Silesh for his valuable comments on the paper. Last, but not least, the authors appreciate Dr Nicole Mohajer for editing the paper.

Contributors Conceived and designed the study: MMM. Acquisition of the data: MMM, YD and AA. Analysed and interpreted the data: MMM and YD. Drafting and critical revision of the manuscript: MMM, YD, and AA. Approved the final manuscript: $M M M, Y D$, and $A A$.

Funding This study received the 2016 Haramaya University annual staff research award.

Competing interests None declared.

Patient consent Not required.

Ethics approval The Institutional Health Research Ethics Review Committee (IHRERC) of Haramaya University, College of Health and Medical Sciences.

Provenance and peer review Not commissioned; externally peer reviewed.

Data sharing statement All data pertaining to the findings are presented in this paper. However, the data can be obtained from the the corresponding author any time on request.

Open access This is an open access article distributed in accordance with the Creative Commons Attribution Non Commercial (CC BY-NC 4.0) license, which permits others to distribute, remix, adapt, build upon this work non-commercially, and license their derivative works on different terms, provided the original work is properly cited, appropriate credit is given, any changes made indicated, and the use is non-commercial. See: http://creativecommons.org/licenses/by-nc/4.0/.

\section{REFERENCES}

1. UNICEF. UNICEF: statistical update 2017. https://data.unicef.org/ topic/hivaids/adolescents-young-people/ (cited 15 Apr 2018).

2. UNICEF. Children and AIDS 2015 statistical update 2015. http://data. unicef.org/resources/children-aids-2015-statistical-update-2/ (cited 12 Apr 2018).

3. UNAIDS/UNICEF/WHO. Global AIDS response progress reporting and UNAIDS 2014 HIV and AIDS estimates, 2015.

4. Mofenson LM, Cotton MF. The challenges of success: adolescents with perinatal HIV infection. J Int AIDS Soc 2013;16:18650.

5. Judd A, Doerholt K, Tookey PA, et al. Morbidity, mortality, and response to treatment by children in the United Kingdom and Ireland with perinatally acquired HIV infection during 1996-2006: planning for teenage and adult care. Clin Infect Dis 2007;45:918-24.

6. Marston M, Zaba B, Salomon JA, et al. Estimating the net effect of HIV on child mortality in African populations affected by generalized HIV epidemics. J Acquir Immune Defic Syndr 2005;38:219-27.

7. WHO. Progress on global access to HIV antiretroviral therapy: a report on "3 by 5" and beyond. Switzerland: World Health Orgabnization, 2006.

8. AAPCP. Disclosure of illness status to children and adolescents with HIV infection. American Academy of Pediatrics Committee on Pediatric AIDS 1999;103:164-6.

9. Wiener L, Mellins CA, Marhefka S, et al. Disclosure of an HIV diagnosis to children: history, current research, and future directions. J Dev Behav Pediatr 2007;28:155-66.

10. Beima-Sofie K, John-Stewart G, Shah B, et al. Using health provider insights to inform pediatric HIV disclosure: a qualitative study and practice framework from Kenya. AIDS Patient Care STDS 2014;28:555-64.

11. Madiba S, Mokgatle M. Perceptions and experiences about selfdisclosure of hiv status among adolescents with perinatal acquired HIV in poor-resourced communities in South Africa. AIDS Res Treat 2016;2016:1-10.

12. Montalto GJ, Sawe FK, Miruka A, et al. Diagnosis disclosure to adolescents living with HIV in rural Kenya improves antiretroviral therapy adherence and immunologic outcomes: A retrospective cohort study. PLoS One 2017;12:e0183180.

13. Tassiopoulos K, Moscicki AB, Mellins C, et al. Sexual risk behavior among youth with perinatal HIV infection in the United States: predictors and implications for intervention development. Clin Infect Dis 2013;56:283-90.

14. Biadgilign S, Deribew A, Amberbir A, et al. Factors associated with HIV/AIDS diagnostic disclosure to HIV infected children receiving HAART: a multi-center study in Addis Ababa, Ethiopia. PLoS One 2011;6:e17572. 
15. Vreeman RC, Scanlon ML, Mwangi A, et al. A cross-sectional study of disclosure of HIV status to children and adolescents in western Kenya. PLoS One 2014;9:e86616.

16. Bikaako-Kajura W, Luyirika E, Purcell DW, et al. Disclosure of HIV status and adherence to daily drug regimens among HIV-infected children in Uganda. AIDS Behav 2006;10(4 Suppl):85-93.

17. Bhattacharya M, Dubey AP, Sharma M. Patterns of diagnosis disclosure and its correlates in HIV-Infected North Indian children. $J$ Trop Pediatr 2011;57.

18. Gerson AC, Joyner M, Fosarelli P, et al. Disclosure of HIV diagnosis to children: when, where, why, and how. J Pediatr Health Care 2001;15:161-7.

19. Sopena S, Evangeli M, Dodge J, et al. Coping and psychological adjustment in adolescents with vertically acquired HIV. AIDS Care 2010;22:1252-8.

20. Vreeman RC, Gramelspacher AM, Gisore PO, et al. Disclosure of HIV status to children in resource-limited settings: a systematic review. $J$ Int AIDS Soc 2013;16:18466.

21. Kallem S, Renner L, Ghebremichael M, et al. Prevalence and pattern of disclosure of HIV status in HIV-infected children in Ghana. AIDS Behav 2011;15:1121-7.

22. Demmer C. Experiences of families caring for an HIV-infected child in KwaZulu-Natal, South Africa: an exploratory study. AIDS Care 2011;23:873-9.

23. Negese D, Addis K, Awoke A, et al. HIV-positive status disclosure and associated factors among children in North Gondar, Northwest Ethiopia. Isrn Aids 2012;2012:1-7.

24. Tadesse BT, Foster BA, Berhan Y. Cross sectional characterization of factors associated with pediatric HIV status disclosure in Southern Ethiopia. PLoS One 2015;10:e0132691.

25. Alemu A, Berhanu B, Emishaw S. Challenges of caregivers to disclose their children's hiv positive status receiving highly active ant retroviral therapy at pediatric anti retroviral therapy clinics in Bahir Dar, North West Ethiopia. J AIDS Clin Res 2013;4(11.

26. CSA [Ethiopia] and ICF International. Ethiopian demographic and health survey. Addis Ababa, Ethiopia, 2012.

27. The Ethiopian Health and Nutrition Research Institute and Federal Ministry of Health. HIV related estimates and projections for Ethiopia-2012. Addis Ababa: Ethiopian Health and Nutrition Research Institute and Federal Ministry of Health, 2012.

28. Namasopo-Oleja M S, Bagenda D, Ekirapa-Kiracho E. Factors affecting disclosure of serostatus to children attending Jinja Hospital Paediatric HIV clinic, Uganda. Afr Health Sci 2015;15:344.

29. Nzota MS, Matovu JKB, Draper HR, et al. Determinants and processes of HIV status disclosure to HIV - infected children aged 4 to 17 years receiving HIV care services at Baylor College of Medicine Children's Foundation Tanzania, Centre of Excellence (COE) in Mbeya: a cross-sectional study. BMC Pediatr 2015;15.

30. Ubesie AC, lloh KK, Emodi IJ, et al. HIV status disclosure rate and reasons for non-disclosure among infected children and adolescents in Enugu, southeast Nigeria. Sahara J 2016;13:136-41.

31. Madiba S. Patterns of HIV diagnosis disclosure to infected children and family members: data from a paediatric antiretroviral program in South Africa. World J AIDS 2012;02:212-21.

32. Britto C, Mehta K, Thomas R, et al. Prevalence and correlates of hiv disclosure among children and adolescents in low- and middle-income countries: a systematic review. J Dev Behav Pediatr 2016;37:496-505.

33. Santamaria EK, Dolezal C, Marhefka SL, et al. Psychosocial implications of HIV serostatus disclosure to youth with perinatally acquired HIV. AIDS Patient Care STDS 2011;25:257-64.

34. Brown BJ, Oladokun RE, Osinusi K, et al. Disclosure of HIV status to infected children in a Nigerian HIV Care Programme. AIDS Care 2011;23:1053-8.

35. WHO. Guideline on HIV disclosure counseling for children up to12 years of age. Geneva, Switzerland: WHO, 2011.

36. FMOH. National guidelines for comprehensive hiv prevention, care and treatment. Addis Ababa, Ethiopia: FMOH, 2014.

37. Kiwanuka J, Mulogo E, Haberer JE. Caregiver perceptions and motivation for disclosing or concealing the diagnosis of HIV infection to children receiving HIV care in Mbarara, Uganda: a qualitative study. PLoS One 2014;9:e93276.

38. Chi-Ling L, Rosemary JL. Disclosure of the diagnosis of HIV/AIDS to children born of HIV-infected Mothers. AIDS Patient Care and STDs 2009;13:5.

39. Oberdorfer P, Puthanakit T, Louthrenoo O, et al. Disclosure of HIV/ AIDS diagnosis to HIV-infected children in Thailand. J Paediatr Child Health 2006;42:283-8.

40. Mweemba M, Musheke MM, Michelo C, et al. "When am I going to stop taking the drug?" Enablers, barriers and processes of disclosure of HIV status by caregivers to adolescents in a rural district in Zambia. BMC Public Health 2015;15:1028.

41. Chilemba E, Phiri C. Ethical aspect of paediatric HIV infection disclosure to perinatally infected children: The Malawi perspectives. International Journal of Africa Nursing Sciences 2017;7:96-105.

42. Marhefka SL, Valentin CR, Pinto RM, et al. "I feel like I'm carrying a weapon." Information and motivations related to sexual risk among girls with perinatally acquired HIV. AIDS Care 2011;23:1321-8. 